\title{
A case of failed awake craniotomy due to progressive intraoperative hyponatremia
}

\author{
Suguru Yamamoto, Hanayo Masaki, Kotoe Kamata ${ }^{*}$, Minoru Nomura and Makoto Ozaki
}

\begin{abstract}
Background: Perioperative seizure control is correlated with a better surgical outcome for awake craniotomy, but some anticonvulsants can induce hyponatremia. Mannitol has also been reported to be hyponatremic.

Case presentation: A 51-year-old right-handed man had malignant glioma in the left parietal lobe. Since anticonvulsant polytherapy did not stop his seizure activity, the daily dose of carbamazepine was increased beginning 17 days before awake craniotomy. The last preoperative blood examination indicated that his plasma sodium level had gradually decreased from 140 to $130 \mathrm{mEq} / \mathrm{L}$. Following skin incision, $200 \mathrm{~mL}$ of 20\% mannitol was administered and his plasma sodium level subsequently dropped to $117 \mathrm{mEq} / \mathrm{L}$. The surgical strategy was changed so that the entire procedure would be performed under general anesthesia because severe intraoperative complications were anticipated.
\end{abstract}

Conclusions: This case suggests that a perioperative electrolyte imbalance caused by drug interactions could be clinically significant for awake craniotomy.

Keywords: Hyponatremia, Awake craniotomy, Mannitol, Carbamazepine

\section{Background}

Hyponatremia is a common disorder that is frequently iatrogenic [1]. In patients with mild chronic hyponatremia, suitably sensitive tests reveal instability in dynamic tasks and attentional impairment [2]. While mannitol is given to neurosurgery patients to reduce intracranial pressure (ICP) $[3,4]$, the optimal conditions of treatment are unclear [5]. The effect of mannitol on ICP is dose-dependent, and its rapid infusion can lead to an electrolyte imbalance [6]. In awake craniotomy, surgeryrelated complications contribute to surgical and functional outcomes [7]. Intraoperative seizure complicates surgery by affecting functional mapping and the patient's level of consciousness. Therefore, careful preoperative loading of anticonvulsants is recommended [8].

In this case, planned awake craniotomy was modified due to progressive hyponatremia.

\footnotetext{
* Correspondence: kamata.kotoe@twmu.ac.jp

This report was previously presented as a poster presentation at the Japan Awake Surgery Conference 2015 annual meeting in Nagoya.

Department of Anesthesiology, Tokyo Women's Medical University, 8-1 Kawada-cho, Shinjuku-ku, Tokyo 162-8666, Japan
}

\section{Case presentation \\ Preoperative course}

A 169-cm, 65-kg, 51-year-old, right-handed man with right-side hemiparesis and dysarthria underwent screening magnetic resonance imaging (MRI) 2 years before craniotomy: a diffuse parietal tumor was misdiagnosed as cerebral infarction. Anticonvulsant polytherapy (carbamazepine, $200 \mathrm{mg}$ daily; levetiracetam, $1000 \mathrm{mg}$ daily) was started for symptomatic epilepsy. Right-hand and oro-facial motor paresis worsened beginning 4 months before surgery, and he was diagnosed with malignant glioma. He was referred to our institution 2 months before surgery. MRI demonstrated a T1 hypointense, T2/fluid-attenuated inversion recovery hyperintense area in the left lower parietal lobe with a gadolinium-positive mass in the postcentral gyrus. ${ }^{11} \mathrm{C}$-methionine positron emission tomography showed a high accumulation of methionine mainly in the postcentral gyrus. The results of a manual muscle test (MMT) showed reduced function (3/5) in his right-upper extremity.

The patient's hypertension was well-controlled with telmisartan (40 mg, daily) and hydrochlorothiazide $(12.5 \mathrm{mg}$, daily). Diabetes was treated with glimepiride ( $1 \mathrm{mg}$, daily) and anagliptin (400 mg, daily). Obstructive sleep apnea syndrome (OSAS) was suspected due to a history of 
snoring. Electrolyte imbalance was not observed. Although carbamazepine was increased to $400 \mathrm{mg}$ daily beginning 17 days before surgery, epileptic seizure in his right-upper limb occurred every 2-3 days. Levetiracetam was increased to $2000 \mathrm{mg}$ daily upon admission 4 days before surgery.

The lesion, suspected grade III glioma according to the World Health Organization (WHO) guidelines [9], was distributed throughout the primary motor and sensory areas of his dominant hemisphere. We chose awake craniotomy using the "Asleep-Awake-Asleep" technique combined with intraoperative MRI for removal of his glioma. Uncontrollable seizure suggested rapid growth of the tumor. The patient was evaluated as American Society of Anesthesiologists (ASA) Physical Status Class 2. While the preoperative blood examination at admission indicated that his plasma sodium level (reference 136-145 mEq/L) had decreased from 140 to $130 \mathrm{mEq} / \mathrm{L}$, he was asymptomatic. Preoperative correction of hyponatremia was ruled out to avoid neurological deterioration due to further growth of the glioma. Additional blood or urine examinations were not performed.

\section{Awake craniotomy}

No premedication was given. Besides standard ASA monitoring, invasive arterial pressure and processed electroencephalogram monitoring were adopted. Following the intravenous administration of $100 \mu \mathrm{g}$ fentanyl, general anesthesia was commenced and maintained with the target-controlled infusion of propofol $(4.0 \mu \mathrm{g} / \mathrm{mL})$ and the continuous infusion of remifentanil $(0.5 \mu \mathrm{g} / \mathrm{kg} / \mathrm{min})$. After several attempts, a supraglottic airway (SGA) was inserted without muscle relaxant. Ventilation was adjusted to maintain an $\mathrm{EtCO}_{2}$ level around $35 \mathrm{mmHg}$. Normal saline and bicarbonate Ringer's solution were given. Scalp blocks and infiltration analgesia were provided with $60 \mathrm{~mL}$ of $0.3 \%$ ropivacaine and $20 \mathrm{~mL}$ of $1 \%$ lidocaine with $0.01 \%$ epinephrine, respectively. Arterial blood gas (ABG) analysis (STAT PROFILE ${ }^{\oplus}$ Critical Care Express; Nova Biomedical, Waltham, MA) after induction showed mild hyponatremia (Table 1, T1).

Hypotension followed by induction was stabilized by three boluses each of ephedrine $4 \mathrm{mg}$ and phenylephrine $0.1 \mathrm{mg}$ until the beginning of surgery. Before dural incision, $200 \mathrm{~mL}$ of $20 \%$ mannitol was administered over $10 \mathrm{~min}$. ABG analysis $117 \mathrm{~min}$ after induction, $25 \mathrm{~min}$ into mannitol infusion, revealed hyponatremia with hyperkalemia (Table 1, T2). Neither pathological electrocardiogram changes nor arrhythmia was observed. Sodium bicarbonate $2.8 \mathrm{~g}$ was given. Glucose-insulin ( $40 \mathrm{~mL}$ of $50 \%$ glucose containing 8 units of insulin) was infused simultaneously with another ABG analysis, which was performed to exclude mechanical failure (Table 1, T3). Hyponatremia was not treated promptly
Table 1 Results of arterial blood gas analysis

\begin{tabular}{|c|c|c|c|c|c|c|c|c|}
\hline & & $\mathrm{T} 1$ & $\mathrm{~T} 2$ & $\mathrm{~T} 3$ & $\mathrm{~T} 4$ & T5 & T6 & $\mathrm{T} 7$ \\
\hline $\mathrm{pH}$ & & 7.397 & 7.392 & 7.401 & 7.403 & 7.415 & 7.431 & 7.440 \\
\hline $\mathrm{PaO}_{2}$ & {$[\mathrm{mmHg}]$} & 214.2 & 218.6 & 218.7 & 220.9 & 222.0 & 226.3 & 220.7 \\
\hline $\mathrm{PaCO}_{2}$ & {$[\mathrm{mmHg}]$} & 35.6 & 36.2 & 35.3 & 37.4 & 35.5 & 31.3 & 32.3 \\
\hline $\mathrm{HCO}^{3-}$ & {$[\mathrm{mmol} / \mathrm{L}]$} & 22.2 & 22.3 & 22.2 & 23.6 & 23.0 & 20.9 & 22.1 \\
\hline $\mathrm{Na}^{+}$ & {$[\mathrm{mEq} / \mathrm{L}]$} & 124.5 & 117.8 & 120.1 & 121.7 & 123.9 & 125.6 & 124.9 \\
\hline $\mathrm{K}^{+}$ & {$[\mathrm{mEq} / \mathrm{L}]$} & 4.30 & 5.58 & 5.82 & 4.41 & 4.25 & 4.41 & 4.62 \\
\hline Glucose & {$[\mathrm{mg} / \mathrm{dL}]$} & 136 & 168 & 169 & 273 & 185 & 160 & 157 \\
\hline
\end{tabular}

T1 = after induction (38 min after induction); T2 = 25 min into mannitol infusion (117 min after induction); T3 = start glucose-insulin therapy (134 min after induction); T4 = after glucose-insulin therapy (191 min after induction); T5 = follow-up analysis ( $236 \mathrm{~min}$ after induction); T6 = follow-up analysis (313 min after induction); T7 = end of surgery (369 min after induction)

because of the risk of central pontine myelinolysis. ABG analysis $191 \mathrm{~min}$ from induction indicated persistent hyponatremia without hyperkalemia (Table 1, T4). In the planned transition to the awake phase, we anticipated insufficient wakefulness, intractable seizure, and deterioration of upper airway patency. Thus, the entire procedure was performed under general anesthesia. The remaining operation was uneventful, although the plasma sodium level remained less than $125 \mathrm{mEq} / \mathrm{L}$ (Table 1, T5-7). Anesthetics were discontinued, and SGA was removed 415 min after induction. The patient's cardiorespiratory status was stable, but the patient could not follow orders. An intravenous transfusion of $1500 \mathrm{~mL}$ bicarbonate Ringer's solution, $300 \mathrm{~mL} \mathrm{1 \%} \mathrm{glucose-containing} \mathrm{acetated}$ Ringer's solution, $650 \mathrm{~mL}$ normal saline, and $200 \mathrm{~mL}$ mannitol was given. Total urine output was $1300 \mathrm{~mL}$, and estimated blood loss was $36 \mathrm{~mL}$. Surgery and anesthesia lasted 433 and $354 \mathrm{~min}$, respectively.

\section{Postoperative course}

The patient regained consciousness $1 \mathrm{~h}$ after the operation. MMTs of his right upper and lower extremities showed $1 / 5$ and $3 / 5$, respectively. Motor aphasia persisted until eight postoperative days (POD), and he walked unaided on POD 24. His plasma sodium concentration normalized by POD 35, before discharge on POD 39. MMTs at discharge were $2 / 5$ and $4 / 5$, respectively. Since the pathological examination revealed an oligoastrocytoma (WHO grade II), he received adjuvant chemotherapy. Prophylactic anticonvulsant polytherapy was continued, and there was no evidence of tumor recurrence at 36 months follow-up.

\section{Discussion}

Though awake craniotomy possibly gives better outcomes than that under general anesthesia, the plasma sodium level must be carefully monitored, because awake craniotomy cannot be achieved if the patient shows neurological sequelae during awake phase. 
While mild hyponatremia (plasma sodium 130$135 \mathrm{mEq} / \mathrm{L}$ ) is generally regarded as asymptomatic, gait disturbance and attentional impairment are often seen [2]. When plasma sodium falls below $125-130 \mathrm{mEq} / \mathrm{L}$, the patient may complain of nausea or malaise. Headache, lethargy, restlessness, and disorientation may occur at $115-120 \mathrm{mEq} / \mathrm{L}$. More severe and rapidly evolving hyponatremia can lead to seizure, coma, or even respiratory arrest [10]. However, aggressive correction of the plasma sodium concentration is not recommended, since it also correlates with neurological sequelae [10]. We were concerned that carbamazepine along with hydrochlorothiazide could cause syndrome of inappropriate antidiuretic hormone secretion (SIADH), though a definitive diagnosis was not obtained due to incomplete laboratory examinations [1, 11]. Also, intraoperative mannitol might have promoted hypertonic hyponatremia by driving fluid from the intracellular to the extracellular space. This case suggests that a plasma sodium disorder must be compensated before surgery; the possibility of hyponatremia-induced neurological symptoms prevented us from switching to the awake phase. Respiratory exacerbation was also anticipated in our OSAS-complicated patient. Intraoperative seizure should be controlled due to the risk of physical harm to the patient. Moreover, Todd paralysis or postictal aphasia due to seizure will preclude awake craniotomy. Therefore, in the Japanese guidelines for awake craniotomy, the anticonvulsant level preceding surgery should be maintained within a therapeutic range [8]. In a retrospective analysis of 477 awake craniotomy cases, preoperative seizure and anticonvulsant polytherapy were related to surgical failure due to intraoperative seizure [7]. Furthermore, patients who experienced seizure during awake craniotomy had a higher incidence of short-term motor deterioration and a longer hospitalization [12]. While anticonvulsant polytherapy is a common strategy for intractable seizure, carbamazepine, valproate, lamotrigine, and oxcarbazepine cause SIADH [13]. Severe hyponatremia is uncommon with a single agent [11]. Preoperative seizure control is important for successful awake craniotomy, and a preoperative electrolyte imbalance, especially hyponatremia, should be treated as much as possible.

Rapid infusion of mannitol increased plasma osmolality, which effected the transcellular redistribution of sodium and potassium. High-dose $(2 \mathrm{~g} / \mathrm{kg})$ mannitol produced a significantly greater decrease in serum sodium than lowdose mannitol (1 $\mathrm{g} / \mathrm{kg}) \quad(-20.7 \quad$ vs. $\quad-8.7 \quad \mathrm{mEq} / \mathrm{L}$, respectively) and a greater increase in serum osmolality [6]. Though these changes recovered to the preoperative level without correction when the patient returned to the recovery room, a serum sodium concentration that started to decline from the beginning of mannitol infusion remained below $130 \mathrm{mEq} / \mathrm{L}$ during craniotomy [5]. In our case, $0.4 \mathrm{~g} / \mathrm{kg}$ mannitol was administered over $10 \mathrm{~min}$, and the plasma sodium concentration was lowest $(117 \mathrm{mEq} / \mathrm{L}) 15 \mathrm{~min}$ after infusion. In awake craniotomy, there is less time between the need for mannitol and patient awakening than with general anesthesia. Accordingly, hypertonic saline (HS) may be a better choice in awake craniotomy. In a recent meta-analysis that compared equiosmolar HS to mannitol during craniotomy under general anesthesia, HS gave better brain relaxation without a significant increase in urine volume [14]. Also, while $3 \%$ HS produced clinically acceptable hypernatremia for $4 \mathrm{~h}$, equiosmolar $20 \%$ mannitol produced hyponatremia for $2 \mathrm{~h}$ [15]. Another clinical study under a standard depth of anesthesia and hemodynamic parameters showed similar results [16]. Thus, HS may replace mannitol due to its ability to increase osmolarity and decrease ICP while maintaining an appropriate serum sodium level for awake craniotomy.

\section{Conclusions}

Plasma sodium affects neurological sequelae; if nausea, restlessness, disorientation, or seizure occurs in an awake patient, awake craniotomy might not be completed. The interactions of perioperative medications and electrolyte imbalances should be carefully monitored.

\section{Abbreviations}

ABG: Arterial blood gas; ASA: American Society of Anesthesiologists; HS: Hypertonic saline; ICP: Intracranial pressure; MMT: Manual muscle test; MRI: Magnetic resonance imaging; OSAS: Obstructive sleep apnea syndrome; POD: Postoperative days; SGA: Supraglottic airway; SIADH: Syndrome of inappropriate antidiuretic hormone secretion; WHO: World Health Organization

\section{Acknowledgements}

The authors are indebted to Yoshihiro Muragaki, M.D., Ph.D. (Department of Neurosurgery, Tokyo Women's Medical University); Takashi Maruyama, M.D., Ph.D. (Department of Neurosurgery, Tokyo Women's Medical University); Taiichi Saito, M.D., Ph.D. (Department of Neurosurgery, Tokyo Women's Medical University); Masayuki Nitta, M.D., Ph.D. (Department of Neurosurgery, Tokyo Women's Medical University); and Atsushi Fukui, M.D., Ph.D. (Department of Neurosurgery, Tokyo Women's Medical University) for their invaluable clinical support.

\section{Funding \\ The present report was supported solely by the hospital and/or departmental sources.}

\section{Authors' contributions}

SY coordinated the patient care and prepared the manuscript. HM managed the anesthetic care of the patient. KK managed the anesthetic care of the patient, prepared the manuscript, and obtained informed consent. MN coordinated the patient care and helped to draft the manuscript. MO coordinated the patient care and helped to draft the manuscript. All authors read and approved the final manuscript.

\section{Authors' information}

SY is a senior resident in the Department of Anesthesiology at Tokyo Women's Medical University. HM is a senior resident in the Department of Anesthesiology at Tokyo Women's Medical University. KK is an assistant professor in the Department of Anesthesia at Tokyo Women's Medical University. MN is a professor in the Department of Anesthesia at Tokyo Women's Medical University. MO is a professor in the Department of Anesthesia at Tokyo Women's Medical University. 


\section{Consent for publication}

Informed consent was obtained from the patient for publication of this case report and any accompanying images. A copy of the written consent is available for review from the Editor-in-Chief of this journal.

\section{Competing interests}

The authors declare that they have no competing interests.

\section{Publisher's Note}

Springer Nature remains neutral with regard to jurisdictional claims in published maps and institutional affiliations.

Received: 12 April 2018 Accepted: 7 May 2018

Published online: 15 May 2018

\section{References}

1. Reynolds RM, Padfield PL, Seckl JR. Disorders of sodium balance. BMJ. 2006:332:702-5

2. Renneboog B, Musch W, Vandemergel X, Manto MU, Decaux G. Mild chronic hyponatremia is associated with falls, unsteadiness, and attention deficits. Am J Med. 2006;119:71. e1-8.

3. Wise BL, Chater N. The value of hypertonic mannitol solution decreasing brain mass and lowering cerebrospinal fluid pressure. J Neurosurg. 1962;19:1038-43.

4. Shenkin HA, Goluboff B, Haft H. The use of mannitol for reduction of intracranial pressure in intracranial surgery. J Neurosurg. 1962;19:897-900.

5. Sorani MD, Morabito D, Rosethal G, Giacomini KM, Manley GT. Characterizing the dose-response relationship between mannitol and intracranial pressure in traumatic brain injury using a high-frequency physiological data collection system. J Neurotrauma. 2008;25:291-8.

6. Manninen PH, Lam AM, Gelb AW, Brown SC. The effect of high-dose mannitol on serum and urine electrolytes and osmolality in neurosurgical patients. Can J Anaesth. 1987:34:442-6.

7. Nossek E, Matot I, Shahar T, Barzilai O, Rapoport Y, Gonen T, et al. Failed awake craniotomy: a retrospective analysis in 424 patients undergoing craniotomy for brain tumor. J Neurosurg. 2013;118:243-9.

8. Kayama T, Guidelines Committee of The Japan Awake Surgery Conference. The guidelines for awake craniotomy. Neurol Med Chir (Tokyo). 2012;52:119-41.

9. Louis DN, Perry A, Reifenberger G, von Deimling A, Figarella-Branger D, Cavenee WK, et al. The 2016 World Health Organization classification of tumors of the central nervous system: a summary. Acta Neuropathol. 2016:131:803-20.

10. Ellis SJ. Severe hyponatremia: complications and treatment. QJM. 1995;88:905-9.

11. Kuz GM, Manssourian A. Carbamazepine-induced hyponatremia: assessment of risk factors. Ann Pharmacother. 2005:39:1943-6.

12. Nossek E, Matot I, Shahar T, Barzilai O, Rapoport Y, Gonen T, et al. Intraoperative seizures during awake craniotomy: incidence and consequences: analysis of 477 patients. Neurosurgery. 2013;73:135-40.

13. Palmer BF, Gates JR, Lader M. Causes and management of hyponatremia. Ann Pharmacother. 2003;37:1694-702

14. Fang J, Yang Y, Wang W, Liu Y, An T, Zou M, et al. Comparison of equiosmolar hypertonic saline and mannitol for brain relaxation during craniotomies: a meta-analysis of randomized controlled trials. Neurosurg Rev. 2017; https://doi.org/10.1007/s10143 01708388

15. Wu CT, Chen LC, Kuo CP, Ju DT, Borel CO, Cherng CH, et al. A comparison of $3 \%$ hypertonic saline and mannitol for brain relaxation during elective supratentorial brain tumor surgery. Anesth Analg. 2010;110:903-7.

16. Ali A, Tetik A, Sabanci PA, Altun D, Sivrikoz N, Abdullah T, et al. Comparison of $3 \%$ hypertonic saline and $20 \%$ mannitol for reducing intracranial pressure in patients undergoing supratentorial brain tumor surgery: a randomized, double-blind clinical trial. J Neurosurg Anesthesiol. 2018;30:171-8.

\section{Submit your manuscript to a SpringerOpen ${ }^{\circ}$ journal and benefit from:}

- Convenient online submission

- Rigorous peer review

Open access: articles freely available online

- High visibility within the field

Retaining the copyright to your article 